\title{
Article \\ Nanos Is Expressed in Somatic and Germline Tissue during Larval and Post-Larval Development of the Annelid Alitta virens
}

\author{
Roman P. Kostyuchenko (i)
}

check for

updates

Citation: Kostyuchenko, R.P. Nanos Is Expressed in Somatic and Germline

Tissue during Larval and Post-Larval Development of the Annelid Alitta virens. Genes 2022, 13, 270. https:// doi.org/10.3390/genes13020270

Academic Editor: David Ferrier

Received: 31 December 2021

Accepted: 28 January 2022

Published: 29 January 2022

Publisher's Note: MDPI stays neutral with regard to jurisdictional claims in published maps and institutional affiliations.

Copyright: (C) 2022 by the author. Licensee MDPI, Basel, Switzerland. This article is an open access article distributed under the terms and conditions of the Creative Commons Attribution (CC BY) license (https:// creativecommons.org/licenses/by/ $4.0 /)$.
Department of Embryology, St. Petersburg State University, 199034 St. Petersburg, Russia; r.kostyuchenko@spbu.ru

\begin{abstract}
Nanos is a translational regulator that is involved in germline development in a number of diverse animals and is also involved in somatic patterning in several model organisms, including insects. Neither germline development nor somatic stem cell lines/undifferentiated multipotent cells have been characterized in the development of the annelid Alitta virens, nor is the mechanism of germ/stem-line specification generally well-understood in annelids. Here, I have cloned an Avi-nanos ortholog from $A$. virens and determined the spatial and temporal expression of Nanos. The results revealed that transcripts of nanos are expressed during differentiation of multiple tissues, including those that are derived from the $2 \mathrm{~d}$ and $4 \mathrm{~d}$ cells. In late embryonic stages and during larval development, these transcripts are expressed in the presumptive brain, ventral nerve cord, mesodermal bands, putative primordial germ cells (PGCs), and developing foregut and hindgut. During metamorphosis of the nectochaete larva into a juvenile worm, a posterior growth zone consisting of nanos-positive cells is established, and the PGCs begin to migrate. Later, the PGCs stop migrating and form a cluster of four nanos-expressing cells located immediately behind the jaws (segments 4-5). During posterior regeneration following caudal amputation, a robust Avi-nanos expression appears de novo at the site of injury and further accompanies all steps of regeneration. The obtained data suggest that blastemal cells are mostly derived from cells of the segment adjacent to the amputation site; this is consistent with the idea that the cluster of PGCs do not participate in regeneration.
\end{abstract}

Keywords: annelids; Nereis; mesoderm; primordial germ cells; PGCs migration; somatic stem cells; neural system; posterior growth zone; foregut; hindgut; regeneration; evolution

\section{Introduction}

Nanos was originally discovered and studied in Drosophila melanogaster [1]. Its homologs encode proteins belonging to a highly conserved protein family found in both vertebrates and invertebrates. One to four nanos genes have been identified across all investigated animal species [2]. Nanos is a translational repressor characterized by a C-terminal domain comprised of two CCHC zinc finger motifs [2].

Expression of this factor is associated with the germline across the Metazoa, and in some cases, Nanos function has been shown to be required for germline development [3-8]. However, based on expression patterns, this gene appears to have multiple roles during embryonic and larval development. Indeed, nanos genes have been shown to play important roles not only in germline development, but also in somatic development [9-11]. Together with piwi, vasa and some other genes, nanos is well known as a member of the germline multipotency program (GMP) genes and a strong molecular marker for the multipotent state of cells [12]. De novo expression of this gene, for example in the regenerative blastema, may indicate local cell dedifferentiation [11,13-17].

Among lophotrochozoans, nanos-related genes show variability in their pattern of expression. In the snail Tritia obsoleta (Ilyanassa obsolete), mRNA of the nanos gene becomes restricted to the $4 \mathrm{~d}$ mesoderm lineage. An experiment using morpholino to knockdown 
nanos resulted in loss of mesodermal and endodermal tissues in the animal [18]. In contrast to Tritia, the vetigastropod Haliotis asinine expresses a nanos homolog in other stages in addition to the early embryonic stage. HasNanos expression is detectable during embryonic and larval development, and, being maternally expressed, it is localized to the micromere cell lineages during early cleavage. Later, HasNanos becomes progressively more prolific in the dorsal quadrant (D) of the embryo. When the trochophore develops, HasNanos mRNA is shown to be expressed in the putative mesodermal bands of the larva and in the primordial germ cells (PGCs) [19]. Among annelids, nanos orthologs are expressed in the germline of the leech Helobdella robusta [20], during gametogenesis in Typosyllis antoni [21], and in PGCs in the polychaetes Platynereis dumerilii and Capitella sp. I [22,23]. These and other studies also report nanos expression in various somatic tissues. For example, in the leech $H$. robusta, nanos expression is detectable in ectodermal stem cells, and Pdu-nanos and CapI-nanos are expressed in multiple somatic tissues, including brain, foregut, mesodermal bands, and the growth zone [20,22-24]. Further, de novo expression of $P d u$-nanos has been reported in regenerating $P$. dumerilii worms [25].

This study examines nanos-related genes in Alitta virens (formerly Nereis virens), a member of the phylum Annelida. Although both early development and regenerative processes in this animal are well-characterized at the morphological level [26-31], the initial stages of germline development and behavior of the PGCs during larval and postlarval development (including regeneration) have not been studied. The use of the nanos gene as a clear molecular marker can be very useful in describing the development of the PGCs. Furthermore, the study of this gene's expression during regeneration will provide additional knowledge about possible cell sources during regrowth of lost body parts in $A$. virens. Thus, in order to begin to investigate the embryonic origin(s) of germline and somatic stem cell lines/undifferentiated multipotent cells that have not been characterized in the annelid A. virens, I have cloned a nanos ortholog (Avi-nanos) and examined its developmental expression patterns by whole-mount in situ hybridization during embryonic, larval, and juvenile stages, and during posterior regeneration.

\section{Materials and Methods}

\subsection{Animals, Experimental Manipulations and Fixation}

Epitoke individuals of $A$. virens were caught during spawning near the Marine Biological Station of SPbSU at the White Sea. Laboratory culture of embryos was obtained by artificial fertilization [26]. When embryos/larvae or juvenile worms reached the preferred stage, they were fixed in $4 \%$ PFA on $1.75 \times$ PBS with $0.1 \%$ Tween 20 at $+4{ }^{\circ} \mathrm{C}$ overnight, then put in $100 \% \mathrm{MetOH}$ for storage at $-20^{\circ} \mathrm{C}$. In laboratory culture, the juveniles grew for 3 months in small aquariums with natural or artificial seawater at $18^{\circ} \mathrm{C}$. Procedures for caudal amputation and cultivation of regenerating juvenile worms have been described previously [30,32,33]. Before amputation of the posterior third of the juveniles' body, the 18-20-segment long animals were anesthetized in a mixture of artificial seawater and $7.5 \% \mathrm{MgCl}_{2}$ (1:1). Worms were washed in filtered artificial seawater and placed into clean, small Petri dishes. The samples were anesthetized again and fixed (see above) at the following time points: $12 \mathrm{~h}$ post-amputation (hpa), 1 day post-amputation (dpa), 2, 3, and 4 dpa.

\subsection{Sequence Retrival and Phylogenetic Analysis}

The sequence of Nanos was found in an unannotated transcriptome database for Alitta virens (local resource). Amino acid alignment of the nanos CCHC zinc finger domain was performed with MUSCLE 3.8.31 [34] using the Phylogeny.fr web server (accessed on 14 January 2022) [35]. Domain organization of the sequences was established using the online program PROSITE (https:/ / prosite.expasy.org/ accessed on 1 December 2021). Bayesian phylogenetic analysis was conducted using the Markov Chain Monte Carlo method implemented in MrBayes 3.2.6 (http:/ / www.phylogeny.fr/ accessed on 14 January 2022) [35-37]. The number of substitution types was fixed to 6 . The Poisson 
model was used for substitution, while rates variation across sites was fixed to "invgamma". Four Markov Chain Monte Carlo (MCMC) chains were run for 100,000 generations, sampling every 100 generations, with the first 250 sampled trees discarded as "burn-in". Finally, a 50\%-majority-rule consensus tree was constructed. The phylogenetic tree was handled using the FigTree program 1.4.4 (http://tree.bio.ed.ac.uk/software/, accessed on 14 January 2022).

\subsection{Gene Cloning}

In order to search for possible additional genes, degenerate PCR with larval $A$. virens cDNA was performed. The sequences for the selected degenerate primers are as follows: upstream primer 5'-TGYGTNTTYTGYMRNAMNAA-3' and downstream primer 5'-GGRCARTAYTTDATNGTRTG-3'. No additional nanos-related gene fragments were identified. For RNA probes for in situ hybridization, a fragment of candidate sequence was isolated by gene-specific PCR and cloned. The sequences for the gene-specific primers are as follows: upstream primer 5'-GTTGTACGGAGATTGGAATCATTGG-3' and downstream primer 5'-GCAACTAGGTCACACGACAGATG-3' . The amplified fragment was $1366 \mathrm{bp}$ in length and included $774 \mathrm{bp}$ of open reading frame (ORF), $48 \mathrm{bp} 5^{\prime} \mathrm{UTR}$, and $544 \mathrm{bp} 3^{\prime} \mathrm{UTR}$. The PCR product was inserted in a pCRII vector by using TOPO-TA cloning (Invitrogen) and used for the transformation of chemically competent E. coli (One Shot ${ }^{\mathrm{TM}}$ TOP10). When colonies with the correct insert were obtained and checked by sequencing, digoxigenin-labeled RNA probes (antisense and sense) were synthesized and used for in situ hybridization.

\subsection{Whole-Mount in Situ Hybridization}

The whole-mount in situ hybridization (WMISH) experiments were performed as described previously [33]. Objects were rehydrated from MetOH then rinsed in PTW, treated with proteinase $\mathrm{K}(100 \mu \mathrm{g} / \mathrm{mL})$ for $0.5-2.5 \mathrm{~min}$ at $+22{ }^{\circ} \mathrm{C}$, twice rinsed in glycine ( $2 \mathrm{mg} / \mathrm{mL})$, postfixed with $4 \%$ PFA on PTW for $20 \mathrm{~min}$. The samples were washed in PTW before the pre-hybridization step. After incubation with the DIG-probe, subsequent washes, overnight incubation with anti-digoxigenin AP antibodies (dilution 1:2500), and washing, the objects were stained with NBT/BCIP, followed by washing in PTW and mounting in $90 \%$ glycerol. In situ hybridization with the sense, DIG-labeled riboprobe was used as a negative control (Supplementary Materials Figure S1).

\subsection{Data Visualization}

Results of in situ hybridization were visualized using DIC optics with an Axio Imager D1 microscope (ZEISS, Oberkochen, Germany). The figures were made in Adobe Illustrator.

\section{Results}

\subsection{Sequence Analysis}

A single nanos fragment was identified in the $A$. virens transcriptome and isolated by gene-specific PCR from $A$. virens cDNA (mixed-stage regeneration); the cDNA sequence is available from GenBank under accession number OL456152. The full-length Avi-nanos transcript encodes a putative protein of 257 amino acids. The Avi-nanos gene possesses two CCHC zinc finger domains that display the highest degree of amino acid identity with other metazoan zinc finger domains from Nanos proteins (Figure 1A). Phylogenetic analysis, based on amino acid alignment of the two CCHC zinc finger domains of the metazoan Nanos proteins, clusters Avi-Nanos with the Nanos from Platynereis and other lophotrochozoan. Obviously, Avi-Nanos is more closely related to vertebrate, cnidarian, and Drosophila sequences than to the Nanos protein of the sponge Ephydatia (Figure 1B). No additional nanos-related genes were isolated by degenerate PCR from larval $A$. virens cDNA. Thus, it is most likely that $A$. virens has a single nanos gene. 
MOTIF

LgiNos

DmeNos

Avinos

PduNos

HasNos

HroNos

Ctenos

PleNos

TtuNos

EmuNos

NveNos 1

NveNos 2

PcaNos2

HvuNos2

$\mathrm{XtrNos} 1$

XleNos 1

MmuNos 1

(A)

gCVFCkkNGE tyeyYs tHvLKDnrGKVvCPILRkYTCPtCqAtGDsAHTqrhCPL hCVFCeNNnEpEaVinSHsvrDnfnRVICPkLRtYvCPICGAsGDsAHTIKYCPk ICVFCktNGEnEmIYsSHvLKeknGRVCCPILRaYkCPnCGAhGDqAHTIKYCPL ICVFCktNGEgEvIYTSHvLKeknGRVCCPILRaYkCPnCGAhGD tAHTIKYCPL ICVFCkNNkEpphVYTgHvLKDs rGy taCPVLRkYpCPICqAiGDhAHTIKYCPf VCVFCRNNkEpEcVanSHlvKDekGqVTCPILY iYTCPICGAtGkaAHTIKYCPy VCVFCRNNGEAE atYTSHqLKDaDGKIVCPVLY IYTCPICGANGPnAHTIKYCPM VCVFCRNNGEAEaVYs SHqLKDPEGaVTCPILY IYTCPICGANGksAHTIKYCPY xCVFCRNNGEAEaVYTSHqLKDPEGaVTCPILY iYTCPICGANGksAHTIKYCPY VCVFCRNNGESE $S$ IYTSHYLKDaEGKVTCPVLRaYTCPLCGANGDgAHTIKYCPe VCVFCRNNGESkkVYsSHVLKDaEGntTCPILRaYTCPLCkAsGsqsHTIKYCPk VCVFCRNNGESE EVYaSHvLKsaDGKtTCPILRaYTCPICkAsGDdsHTIKYCPq VCVFCRNNGESE SVYTSHVLKDaDGRTaCPILRAYTCPICKANGDnsHTIKYCPM VCVFCRNNGESEnVYaSHVLKD tDGRtSCPILRaYTCPICkANGDnsHTIKYCPM gCgFCRsNrEAQs IYsSHrLrapDGRVICPVLRgYTCPLCGANGDWAHTmrYCPL gCgFCRsNrEAls IYTSHrLralDGRVICPVLRgYTCPLCGANGDwAHTmrYCPL VCVFCRNNkEAva IYT tHiLKgPDGRVICPVLRYYTCPLCGASGDNAHTIKYCPL HsaNos1 VCVFCRNNkEAma IYT tHiLKgPDGRVICPVLRrYTCPLCGAs GDnAHTIKYCPL

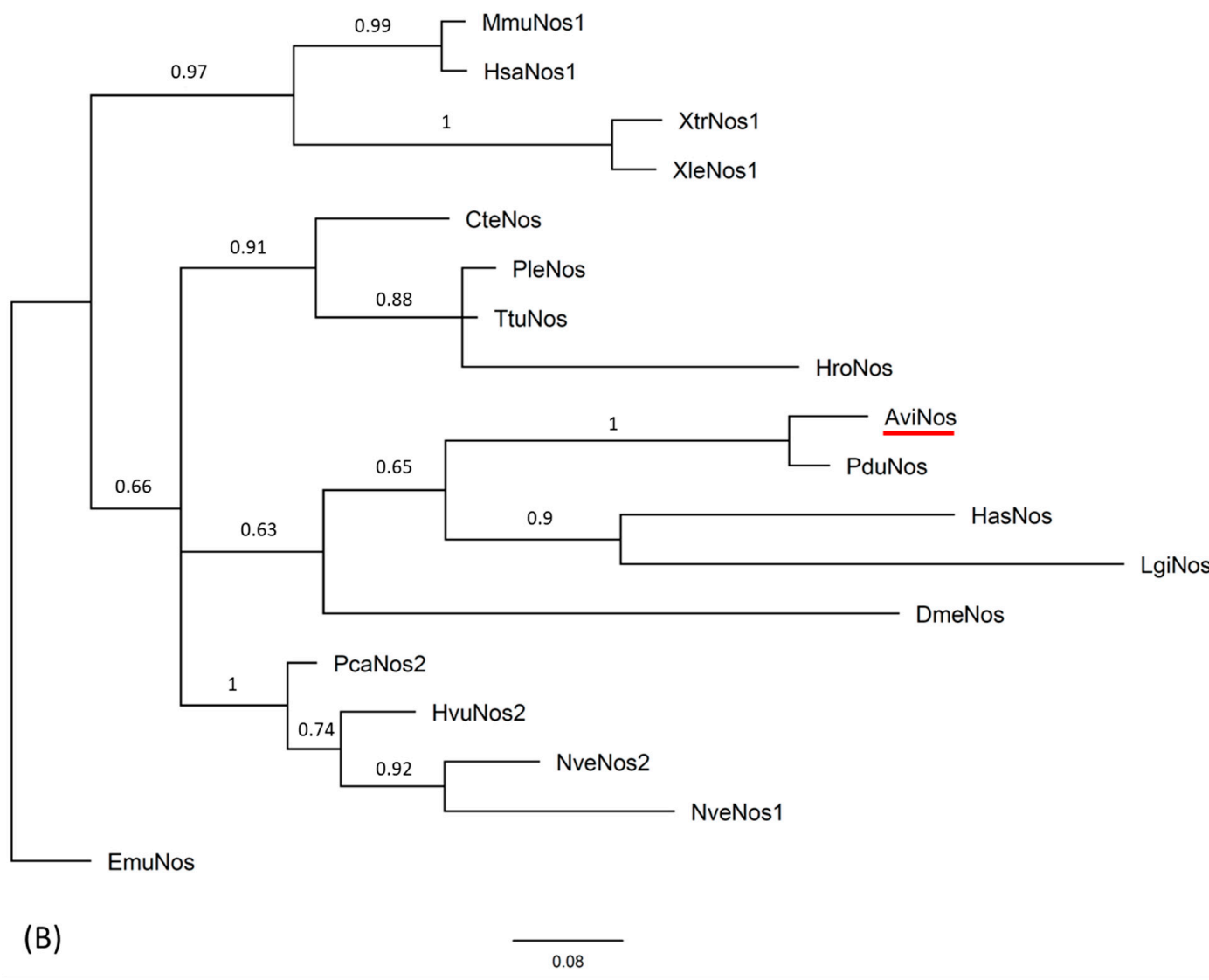

Figure 1. Sequence alignment and phylogenetic analysis of nanos gene from Alitta virens. (A) Multiple sequence alignment of AviNos (underlined in red) with other Nanos zinc finger domain sequences from vertebrates and invertebrates. (B) Phylogenetic analysis of Alitta virens nanos gene. Bayesian consensus tree of the CCHC zinc finger domain of metazoan nanos genes: AviNos (Alitta virens, GenBank OL456152); CteNos (Capitella teleta, DAA06318.1); DmeNos (Drosophila melanogaster, AAA28715.1); Emu (Ephydatia muelleri, AJE59349.1); HasNos (Haliotis asinine, ACT35656.1); HroNos (Helodbella robusta, AAB63111.1); HsaNos1 (Homo sapiens, NP_955631.1); HvuNos2 (Hydra vulgaris, BAB01492.1); LgiNos (Lottia gigantean, XP_009044182.1); MmuNos1 (Mus musculus, NP_848508.2); NveNos1 (Nematostella vectensis, AAW29070.1); NveNos2 (Nematostella vectensis, AAW29071.1); PcaNos (Podocoryne carnea, AAU11514.1); PduNos (Platenereis. Dumerilii, CAJ28985.1); PleNos (Pristina leidyi, ADE44350.1); TtuNos (Tubifex tubifex, BAQ21630.1); XleNos1 ((Xenopus laevis, NP_001081503.1); XtrNos1 (Xenopus tropicalis, NP_988857.1). 


\subsection{Avi-nanos mRNA Larval and Juvenile Expression Patterns}

Avi-nanos expression was examined by WMISH throughout embryonic and larval development, metamorphosis, and at several growth stages of juvenile A. virens. Avi-nanos transcript is detected in the yolk-free cytoplasm in zygotes. After the completion of ooplasmic segregation, Avi-nanos mRNA is found in the animal hemisphere (Figure 2A) of the zygotes. Through early cleavage stages, the transcript is detected in most, if not all, blastomeres of all four embryonic quadrants (Figure 2B). Later, expression of Avi-nanos significantly decreases, and strong expression is only observed in few very small cells ( $4 \mathrm{~d}$ daughter cells), although it is also detected at much lower levels throughout the embryo (Figure 2C). As mesodermal band formation progresses, the level of the transcripts becomes noticeably higher in the $4 \mathrm{~d}$ descendant cells (Figure 2D,E). At the end of gastrulation, Avi-nanos expression is observed in a more discrete pattern with four distinct domains, including epidermal cells of the hyposphere, the presumptive brain, the closing blastopore, and mesodermal cells (Figure 2F-H).

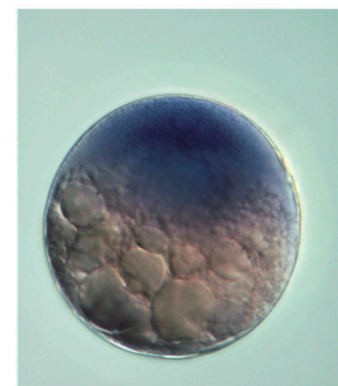

A

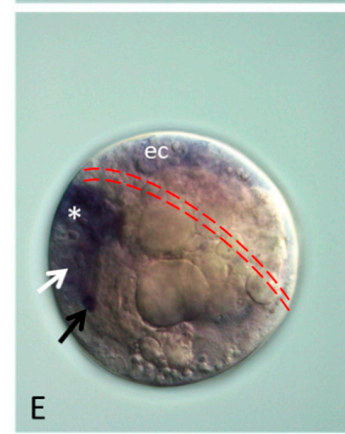

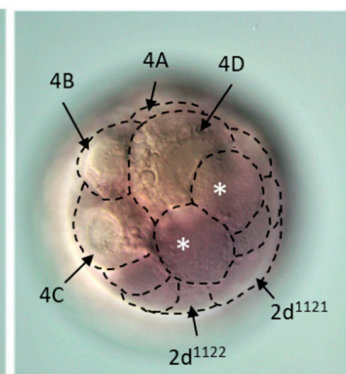

B

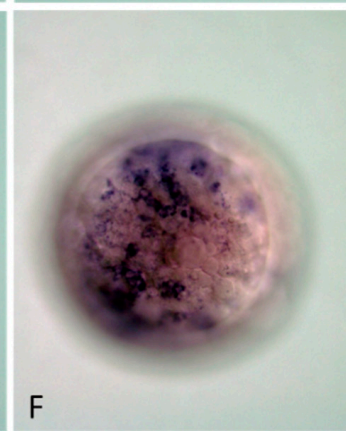

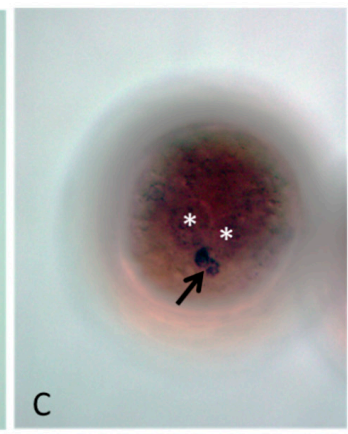

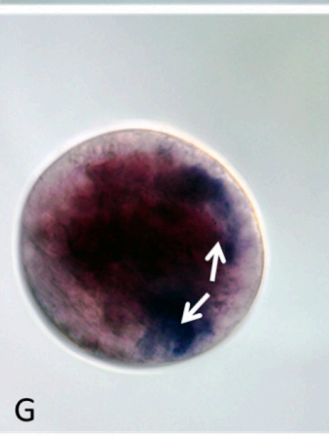

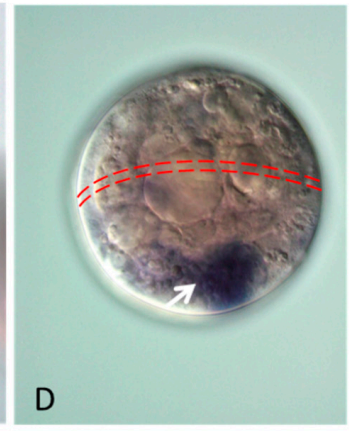

D

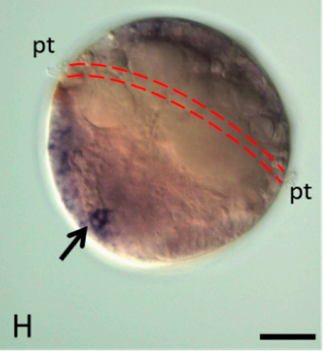

Figure 2. Avi-nanos RNA expression patterns during embryonic and trochophore larva development. (A) Zygote after completion of ooplasmic segregation. Avi-nanos RNA is detected in the yolk-free cytoplasm of the animal hemisphere. (B) Cleavage stage. Avi-nanos transcript is observed in almost all blastomeres, including the $4 \mathrm{~d}$ daughter cell: white asterisks indicate mesoteloblast; black dotted lines highlight the blastomeres. (C) Early gastrulation stage, superficial vegetal view. Strong expression is observed in small cells, putative primordial germ cells (PGCs) (arrow), descendants of mesoteloblasts (asterisks). (D) Mid-gastrula stage, lateral view, ventral on the left, animal pole facing up. Expression in the mesoteloblasts and forming mesodermal bands (arrow). The position of the presumptive prototroch is marked by double red dotted line. (E) Late gastrulation-early trochophore, lateral view in a deep focal plane, ventral on the left, animal pole upward. Expression in the mesodermal bands (white arrow), stomodeal cells (asterisk), epidermal cells of the episphere (prospective brain cells, ec), and putative PGCs (black arrow). The position of the presumptive prototroch is marked by double red dotted line. (F) Trochophore, anterior view in a surface focal plane, ventral to the left. Avi-nanos expression in the presumptive brain. (G) Trochophore, anterior-ventral view in a deep focal plane. Expression in the bilateral mesodermal bands (arrows). (H) Late trochophore, lateral view in a deep focal plane, ventral on the left. Expression in the ventral plate (hyposphere), hindgut region, including putative PGCs (arrow), and epidermal cells of the episphere. The position of the prototroch is marked by double red dotted line: $p t$, ciliated cells of the prototroch. Scale bar, $40 \mathrm{mkm}$ for all panels. 
From the trochophore stage when the ventral plate is formed in the hyposphere, a robust expression of Avi-nanos is observed in the anlage of the ventral nerve cord. During metamorphosis of the trochophore into the metatrochophore, the number of such cells increases significantly (Figure 3A). The midline expression domain is confined to the apical cell layers (Figure 3D,G). This expression is gradually restricted first to two bilateral cell domains at the ventral midline, which correspond to the subsets of the neuroblast cells (metatrochophore stages), and later to single cells in every segmental ganglion in nectochaete larvae (Figure 3D; Figure 4B).

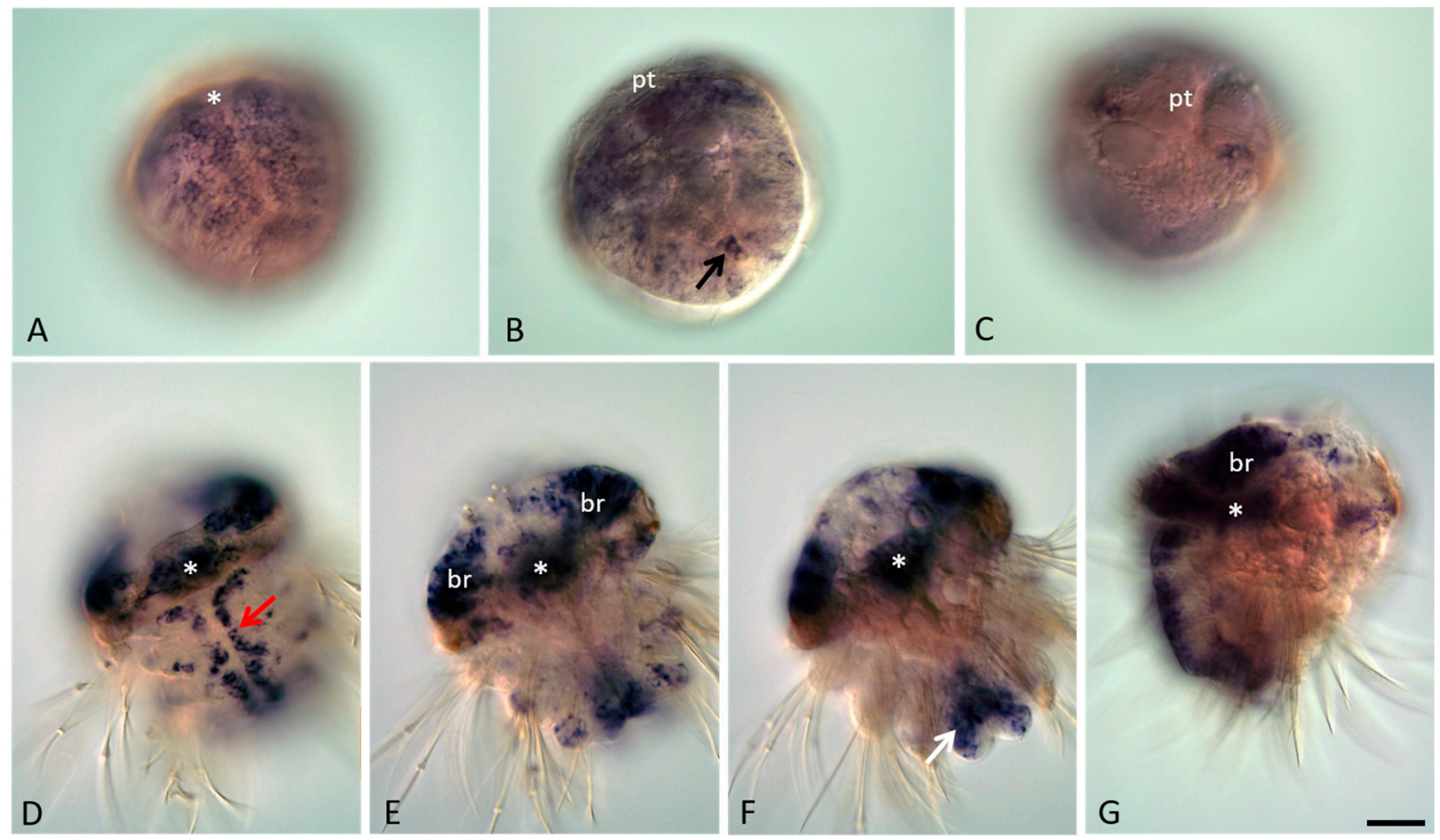

Figure 3. Avi-nanos RNA expression patterns during metatrochophore larva development. Except for $(\mathbf{C}, \mathbf{G})$, all animals are oriented anterior to the upper left corner. $(\mathbf{A}-\mathbf{C})$ Early metatrochophore at different focal planes; (D-G) Late metatrochophore at different focal planes. (A) Avi-nanos is broadly expressed in most cells of the ventral plate, including the forming stomodeum (foregut anlage) and in the presumptive neuroectoderm; ventro-caudal view in a surface focal plane. (B) A nanos transcript is observed in the developing chaetal sacs and proctodeum (hindgut anlage), where putative PGCs are located (arrow); ventro-caudal view, deeper. (C) Dorsal surface view, anterior upward. (D) Robust Avi-nanos expression is detected in the stomodeum, ventral nerve system, and putative peripheral neurons; ventral view in a surface focal plane. (E) Expression in the brain, stomodeum, and the putative parapodial neurons; ventral view, deeper. (F) Expression in the anal lobes and the hindgut (arrow). (G) A deep lateral view of the late metatrochophore, anterior upward, ventral to the left. white asterisk mark position of stomodaeum: $b r$, brain, $p t$, prototroch. Scale bar, $40 \mathrm{mkm}$ for all panels.

Avi-nanos is expressed in the presumptive brain through larval development, including during the late nectochaete stage when the brain is morphologically distinct from the overlying ectoderm (Figure 3E,G; Figure 4A). Expression in the brain is reduced towards the end of metamorphosis of the nectochaete larva into a four-segmented juvenile worm, but it is still detected at later developmental stages (Figure 4D,E,H). Avi-nanos transcript is observed in the foregut during very early stages of foregut development; it is found in cells that correspond to some cells around the closing blastopore at the early trochophore stage (not shown). Robust foregut expression is detected at the metatrochophore stages (early, 
middle, and late metatrochophore) and at low levels at the nectochaete stage (Figure 3D-G; Figure 4D). Avi-nanos is also expressed for a short period in the hindgut during the early and middle metatrochophore stages (Figure 3F,G). At these stages, the pygidial lobes start to form, almost all cells of which show nanos transcripts. A set of Avi-nanos-positive cells are also apparent immediately anterior to the ciliated telotroch at the posterior end of the larvae. These cells are ectodermal cells that form a band around most of the circumference of the larva. The position of these cells corresponds to the future posterior growth zone.
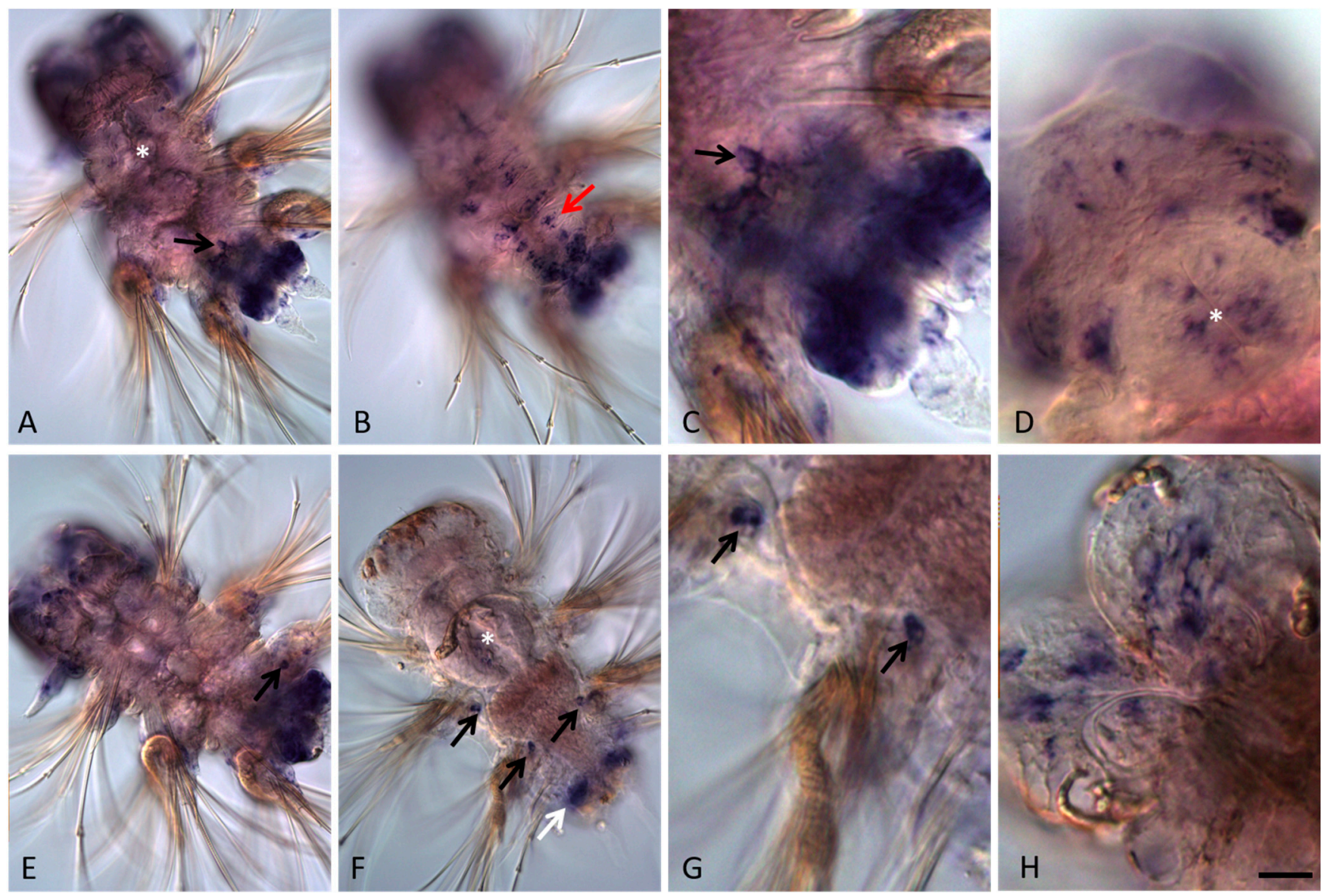

Figure 4. Avi-nanos RNA expression patterns during nectochaete larva development and metamorphosis into a four-segmented juvenile worm. All animals are oriented anterior to the upper left corner. (A-D) Nectochaete at different focal planes; (E-H) juvenile animals at different focal planes. (A) Avi-nanos is broadly expressed in most caudal area that corresponds with the future posterior growth zone, and in the putative PGCs (arrow). (B) Expression in the ventral nerve cord (arrow); ventral view in a more surface plane. (C) Enlarged view of the caudal region of the nectochaete shown in (A); dorsal surface view, anterior upward. (D) Expression in the pharynx and in the head; view from dorsal side. (E,F) Expression in the growth zone and the next-forming segment (white arrow). Migrating PGCs (black arrows); deep ventral view. (G) Enlarged view of the migrating PGCs shown in (F). (H) Expression in the brain. * marks the pharynx. Scale bar, $40 \mathrm{mkm}(\mathbf{A}, \mathbf{B}, \mathbf{E}, \mathbf{F}) ; 13 \mathrm{mkm}(\mathbf{C}, \mathbf{G}, \mathbf{D})$; or $16 \mathrm{mkm}(\mathbf{H})$.

At the end of larval development, four small, roundish nanos-positive cells emerge from the posterior (hindgut) region and begin migrating anteriorly (Figure 4A,C,F,G). During the 4-5-segmented juvenile worm stage these cells can be found in various positions, usually close to the parapodia base, but they are never observed in the cephalic segment, which will later be integrated into the head. A cluster of four nanos-expressing cells located right behind the jaws (segments 4-5) is detected in 18-20-segment long juvenile worms (Figure 5I). All juveniles studied in this work (4-5 and 18-20-segment long animals) are 
characterized by robust Avi-nanos expression in the posterior growth zone and in the newly formed postlarval segments (Figure 5A-C,F). The number of the nanos-positive cells (both superficial and internal) is especially high on the ventral side. Expression of Avi-nanos is also detected in the ventral cells of the nervous system in almost all body segments in juvenile $A$. virens (Figure 5A,B,D) and in the individual cells of both the ventral and dorsal parts of parapodia (Figure 5E,H). Domains of Avi-nanos mRNA localization are found in the head, including eye regions, and the peristomial cirri (Figure 5G).
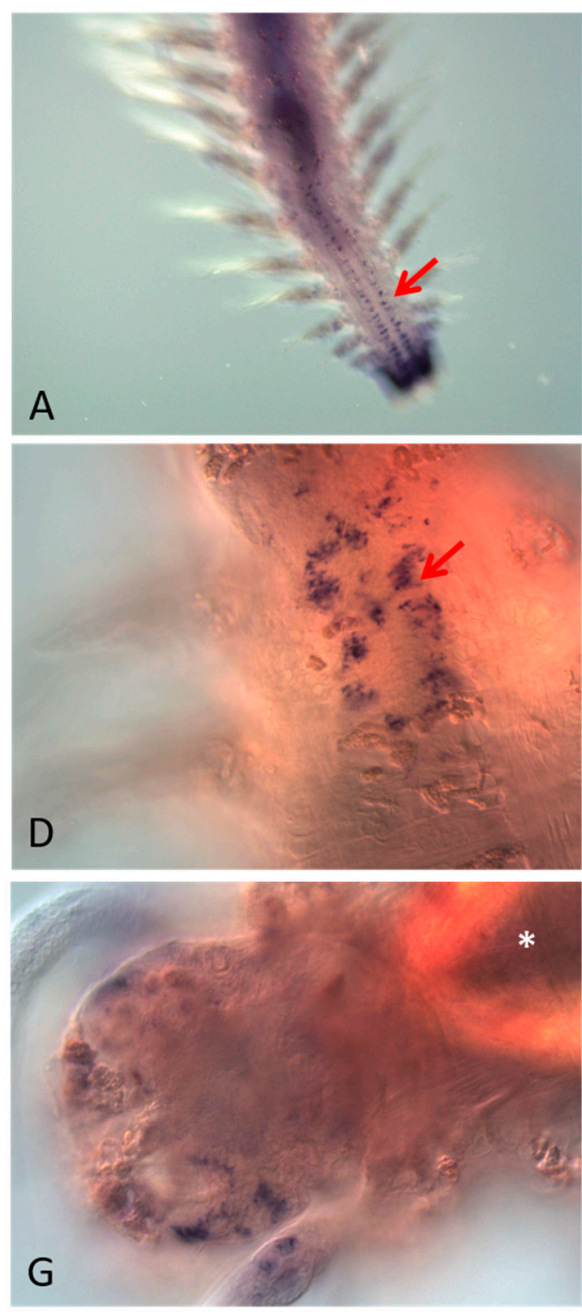
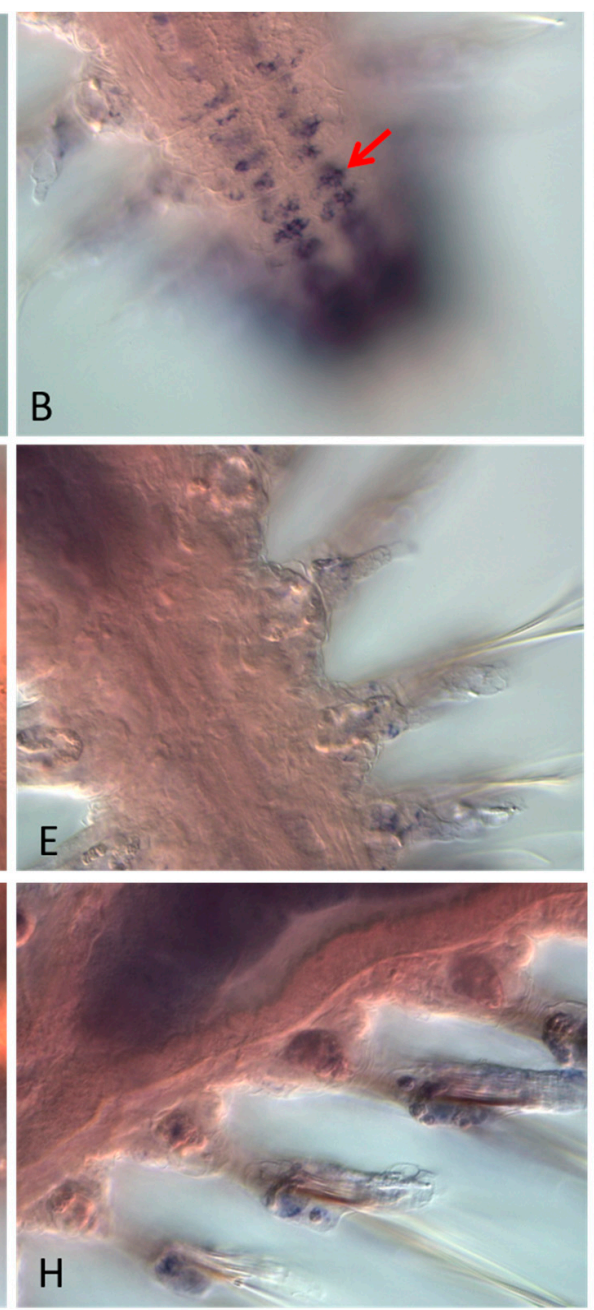
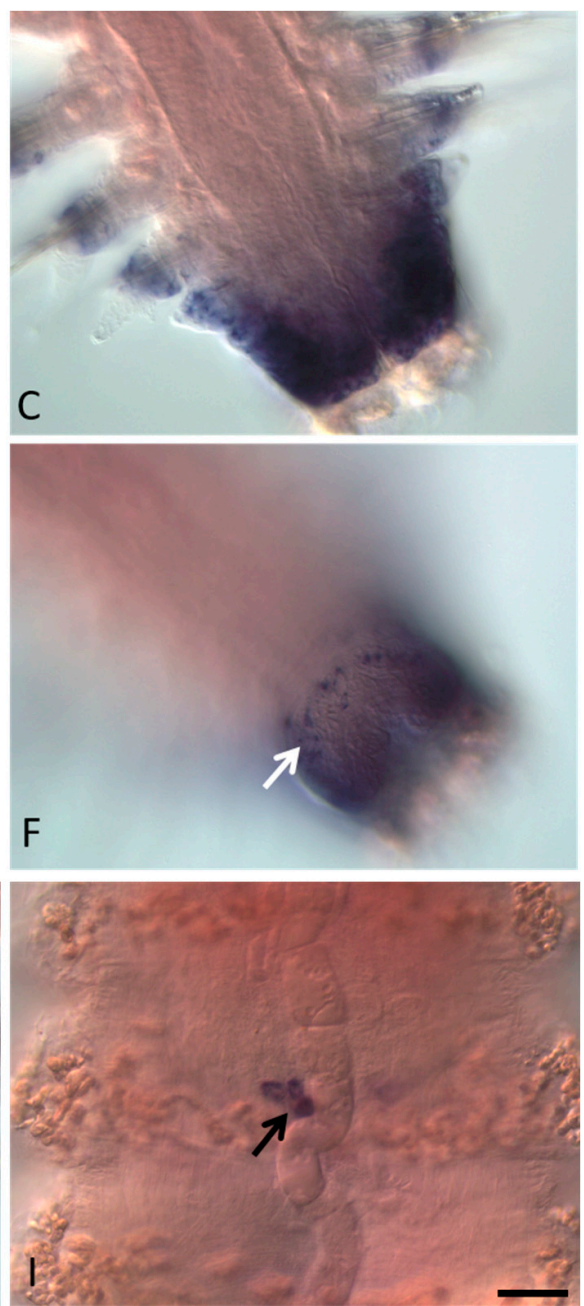

Figure 5. Avi-nanos RNA expression patterns in the 18-20 segment-long juvenile worms. Except for $(\mathbf{G}, \mathbf{H})$, all animals are oriented anterior upward; in $(\mathbf{G}, \mathbf{H})$ anterior is down and left. (A) Avi-nanos is broadly expressed in the posterior growth zone, newly developed segments, and the ventral nerve cord (arrow); ventral view. (B) Enlarged view of the caudal region of the animal shown in (A); (C) image (B) in a different focal plane. (D) Expression in the cells of the ventral nerve cord (arrow), anterior segments; ventral view. (E) Expression in the parapodia, ventral view. (F) Expression in epidermal cells of the growth zone (arrow); dorsal view. (G) Expression in the head and the peristomial cirri; dorsal view. (H) Expression in the parapodia; dorsal view. (I) A cluster of nanosexpressing cells (PGCs) located right behind the jaws (arrow). * marks the pharynx. Scale bar, $40 \mathrm{mkm}$ for all panels except (A). Scale bar in (A), $85 \mathrm{mkm}$.

\subsection{Avi-nanos Expression during Regeneration after Caudal Amputation}

In experimental conditions, after amputation, $A$. virens juveniles are able to restore the pygidium, growth zone and the lost segments after several days. Although the complete regeneration takes 5 to 10 days, formation of the first restored segment usually occurs $4 \mathrm{dpa}$. At the site of the amputation, Avi-nanos expression is detected $12 \mathrm{hpa}$, before the completion 
of wound healing. It appears de novo in both superficial cells and internal cells, mostly on the ventral site of the wound (Figure 6A, B). Obviously, no nanos transcripts are visible in the injured gut epithelium (Figure 6C). Later, at the 1 dpa stage, when the wound healing is complete, expression of Avi-nanos is found in the forming posterior blastema (not shown). At the 2 dpa stage, domains of both the ventral epidermal and internal nanos-positive cells grow significantly (Figure 6D,E). At this point in time, the epidermal cells on the dorsal side of the regeneration also show expression, but at a very low level (Figure 6F).
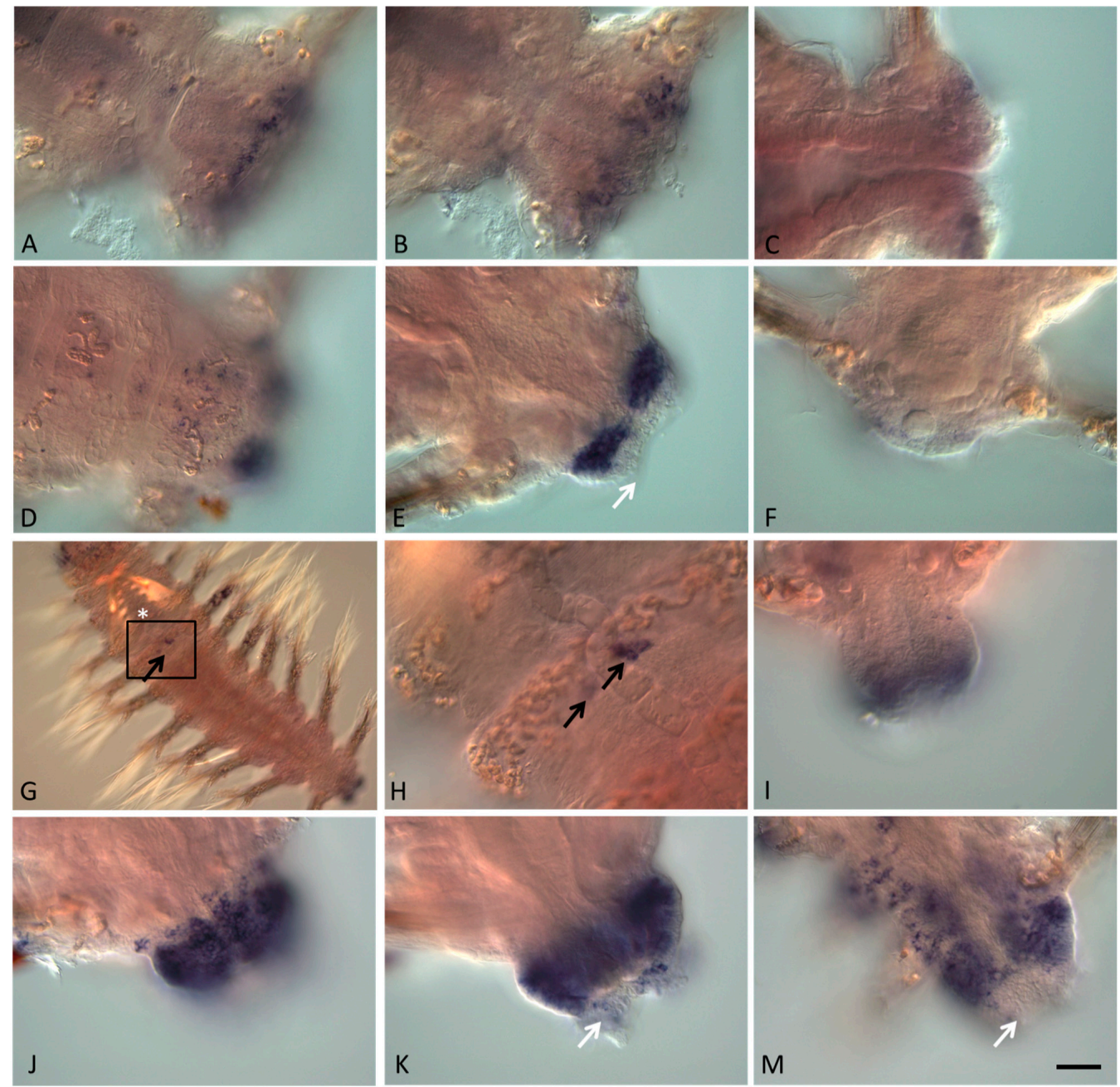

Figure 6. Avi-nanos RNA expression patterns during posterior regeneration. Except for (C,F), all animals are oriented anterior to the upper left corner; in $\mathbf{C}$ anterior is to the left; in $\mathbf{H}$ anterior is up. The pictures show the following stages of regeneration: (A-C) 12 hpa; (D-F) 2 dpa; (G-K) 3 dpa; (M) 4 dpa. (A) Avi-nanos is expressed in cells at the wound site; ventral view. (B) The same animal; deeper focal plane. (C) Dorsal view, deep. (D) Expression in the neural ganglia cells; ventral view. (E) A robust expression of nanos is detected in the epidermal and blastemal cells of the regeneration bud, except for the most terminal dorsal region of the pygidium anlage (arrow); ventral view, deeper. (F) Expression in epidermal cells of the forming growth zone; dorsal view. (G) Expression in the head, parapodia, regeneration bud, and in a cluster of four nanos-expressing cells (PGCs; arrow) located right behind the jaws (denoted by *). (H) Enlarged view of the boxed region shown in $(\mathbf{G})$ highlighting a cluster of PGCs (arrows). (I) Expression in epidermal cells of the forming growth zone; dorsal view. $(\mathbf{J}, \mathbf{K})$ Expression during the beginning of the first restored segment formation; ventral view, different focal planes. A weak expression persists in growing pygidial cirri (arrows). (M) Progression of regeneration is accompanied by increased Avi-nanos expression in the cells of the nerve ganglia of the surviving segments adjacent to the amputation plane; ventral view. Expression disappears in the new pygidium (arrows). Scale bar, $40 \mathrm{mkm}$ for all panels except (G). Scale bar in (G), $85 \mathrm{mkm}$. 
During the next day of the experiment, the regeneration bud shows noticeable growth due to active proliferation of the epidermal and blastemal cells, especially on the ventral and lateral sides [31,32]. At this stage, Avi-nanos mRNA is detected in almost all cells of the regeneration bud, except for the most terminal end, where the anal cirri form (Figure 6J,K). Although the level of Avi-nanos in most dorsal cells is still very low, there are some cells that are characterized by increased transcript levels (Figure 6I). These dorsal cells, together with the ventral and lateral cells, form a new posterior growth zone. Already at the 3 dpa stage, especially dense domains of nanos-positive cells adjacent to the surviving posterior segment (Figure 6K) become visible, and a new segment begins to develop.

Interestingly, during regeneration, Avi-nanos mRNA can be observed in the ventral nerve cord ganglia of almost all segments, however, the number of nanos-positive cells decreases markedly (Figure 6D). Nevertheless, in the two days after initiation of the development of the first new segment, expression in the ventral nervous system again increases significantly (Figure 6M). The cluster of nanos-expressing cells located right behind the jaws retains its position and composition throughout the period of pygidium recovery, growth zone formation, and the beginning of production of new segments (Figure 6G,H). Meanwhile, the character of Avi-nanos expression in the parapodia and in the head remains unchanged (Figure 6G). No signs of migration of nanos-expressing cells were found.

\section{Discussion}

In this work an ortholog of the nanos gene family (Avi-nanos) was isolated from the annelid $A$. virens, and its developmental expression patterns were examined by wholemount in situ hybridization during the embryonic, larval, and juvenile stages, and during posterior regeneration. It has been shown that a nanos homolog is expressed in both germline and in multiple somatic tissues during $A$. virens development. Avi-nanos mRNA is shown in the brain, ventral nerve cord, foregut, hindgut, mesodermal bands, and posterior growth zone, and appears de novo in blastema during regeneration.

Similar to most lophotrochozoans that have been studied (except for P. dumerilii, s. below), Avi-nanos transcript is detected in the yolk-free cytoplasm in uncleaved zygotes, which indicates maternal expression without specific asymmetric localization [18-20,23,38-40]. Further distribution of the nanos gene product in most blastomeres of all four quadrants suggests the absence of the effect of ooplasmic segregation $[27,28]$ on the inheritance of the maternal transcript by specific blastomeres. Similar to Capitella [23], expression of Avi-nanos is enriched in $4 \mathrm{~d}$ daughter cells at the fifth to sixth cleavage, although it is also detected at lower levels throughout the embryo. This pattern contrasts with the restricted nanos expression at a similar stage in the snail, T. obsoleta [18]. Indeed, during the first five cleavage cycles, nanos mRNA is found in all cells of the Tritia embryos. However, between the 24- and 36-cell stages, IoNanos mRNA becomes restricted to two cells: the yolk-rich $4 \mathrm{~d}$ macromere and the $4 \mathrm{~d}$ micromere; later it is specifically localized in the mesendodermal blast cells derived from the $4 \mathrm{~d}$ blastomere. On the other hand, a broad expression of a nanos homolog is found in the early embryo of the vetigastropod H. asinine. HasNanos expression is detectable during embryonic and larval development-being maternally expressed it is localized to the micromere cell lineages during early cleavage [19]. In the annelid A. virens, at the sixth to seventh cleavage, a robust expression is detected in very small cells, although it is also detected at lower levels throughout the embryo. These cells are products of the first cell divisions of the mesoteloblasts (4d daughter blastomeres) [41] and are putative PGCs [41-45]. A broad Avi-nanos expression encompasses all 4d descendants, not only those which will give rise to the primordial germ cells but also the major derivative of mesoteloblasts: segmental mesoderm, which includes body wall, visceral muscle, and coelomic cavity linings. In the oligochaete annelid Tubifex tubifex, a broad expression of Ttu-nos throughout the early cleavage stages (up to the 22-cell stage) becomes restricted to $2 \mathrm{~d}$ and $4 \mathrm{~d}$ cells. After teloblast formation, it is detected in nascent primary blast cells produced by mesodermal teloblasts $\mathrm{M}$ and ectodermal teloblasts $\mathrm{N}$ and $\mathrm{Q}$ [40]. In the glossiphoniid leech embryo (Helobdella robusta), a high level of Nanos protein was detected in ectodermal 
precursor cells during cleavage, but with lower expression levels in mesodermal precursors. Thus, the leech nanos lacks restricted expression in the $4 \mathrm{~d}$ lineage [38].

When the trochophore develops, Avi-nanos mRNA is shown to be expressed in the putative mesodermal bands of the larva, similar to Capitella, Platynereis, Tritia, and Haliotis, and in the PGCs, similar to Capitella, Platynereis and Helobdella [18-20,22,23]. Interestingly, further nanos expression in polychaetes is not restricted to mesodermal derivatives. Strong expression is shown in the epidermal and neural structures, the forming foregut and hindgut, parapodia cells, and the growth zone, including its ectodermal component [22,23] and this study. During metamorphosis of the A. virens trochophore into the metatrochophore, when the larval body extends along the anterior-posterior axis by ventral plate growth due to convergence of cells from lateral sides, as well as by proliferation within the ventral plate itself, the epidermal domain of Avi-nanos expression is especially broad. Later, at the nectochaete stage, it becomes more restricted to the forming growth zone. Avi-nanos-positive putative PGCs migrate anteriorly through the parapodia base at the late nectochaete-juvenile stage. Positions of the Avi-nanos-expressing PGCs in nectochaete and juvenile stages vary to a high degree. Later, they form a cluster of four nanos-expressing cells located right behind the jaws (segments 4-5). In the first study on Platynereis, the $P d u$-nanos transcript was not detected in the zygote, during early cleavage, or at the juvenile stages [22]; most likely this was due to technical issues. Later, a strong Pdu-nanos gene expression was shown in juveniles and regenerates of P. dumerilii [24,25]. Obviously, the maternal phase of gene expression, as well as a varied pattern of zygotic expression in both the germline and somatic cells, is a common feature of annelid development.

Expression of nanos homologs during annelid regeneration has not been adequately studied. In the oligochaete Pristina leidyi, PRIle-nanos is strongly expressed in the posterior growth zone. Its expression appears de novo in the fission zone during asexual reproduction and in the blastema cells during anterior and posterior regeneration [46,47]. In Alitta, as well as in Platyneres, the nanos transcript appears de novo at the wound site during the early stages of regeneration [this study, 25]. According to our previously published data, other GMP genes (Avi-pl10, Avi-vasa, Avi-piwi1, and Avi-pizwi2) also start their expression de novo at the injury site during $A$. virens posterior regeneration [32]. Transcripts of pl10, vasa, piwi, and nanos homologs are detected at all steps of caudal regeneration. Similar to Avi-pl10, Avi-vasa, and Avi-piwi1, Avi-nanos mRNA is broadly distributed across the whole regeneration bud, while Avi-piwi2 signal is found exclusively in the blastema. In Alitta, expression of the studied GMP genes becomes especially strong during blastema growth and differentiation ( $2-3 \mathrm{dpa}$ ). This period is characterized by active cell proliferation across the regeneration bud and formation of the new growth zone [30-32]. Later, when new segment primordia have become apparent, expression of Avi-vasa and Avi-piwi2 gradually fades in the nascent segments, while Avi-nanos, Avi-pl10, and Avi-piwi1 are still broadly expressed in the regenerating posterior end of the worm. These differences in gene expression correspond to observed patterns in unamputated, growing juvenile worms [32] this study. In contrast to other GMP genes from A.virens, Avi-nanos is also detected in the ventral nerve cord ganglia of almost all segments, although the number of nanos-positive cells decreases markedly during the first few days of regeneration. No signs of nanospositive cell migration were found, and the cluster of nanos-expressing PGCs located right behind the jaws remains unchanged. The obtained results show the expression of a pluri/multipotent stem cell marker (nanos) in the blastema from an early stage. These data also support the opinion that blastemal cells are mostly derived from cells of the segment adjacent to the amputation site, and that the cluster of PGCs is not required for regeneration in the nereid polychaetes $[24,32,45]$.

Local cell dedifferentiation, rather than the migration of stem cells, is considered the source of the blastema in most polychaetes [32,48,49]. However, the molecular signals that induce the blastema precursor cells in annelids have not been identified yet. Our recently published data suggest that FGF is essential for blastema formation and regeneration in A. virens [31]. At the 4 hpa stage, expression of the FGF genes is already found in the surface 
cells, nervous system and mesodermal cells at the injury site. In $A$. virens, FGF inhibitors prevent regeneration, most likely by suppression of cell proliferation and blastema initiation. On the other hand, GMP genes (vasa, pl10, piwi, and nanos) have an extensive expression in FGF-competent tissues starting at day 2 of $A$. virens posterior regeneration. This suggests that FGFs in $A$. virens may also affect premature cell differentiation during blastema growth and patterning [31]. Thus, FGF signals are possible candidates for reprogramming cell fates in annelid regeneration. Further studies will show if FGF inhibitors affect expression of nanos and other GMP genes during $A$. virens regeneration.

Supplementary Materials: The following supporting information can be downloaded at: https: / / www.mdpi.com/article/10.3390/genes13020270/s1, Figure S1: Results of in situ hybridization with the sense Avi-nanos DIG-labeled probe (negative control).

Funding: This research was funded by RSF grant 17-14-01089 (gene identification, bioinformatics analysis) and RFBR grant 19-04-01111-a (gene cloning and expression analysis).

Institutional Review Board Statement: Not applicable.

Informed Consent Statement: Not applicable.

Data Availability Statement: mRNA sequence of Avi-nanos is deposited in GenBank with the accession number OL456152.

Acknowledgments: I am grateful to Vitaly Kozin for assistance with obtaining the A. virens materials. This research was performed at the Research Park of Saint Petersburg State University "Center for Molecular and Cell Technologies".

Conflicts of Interest: The author declares no conflict of interest.

\section{References}

1. Irish, V.; Lehmann, R.; Akam, M. The Drosophila posterior-group gene nanos functions by repressing hunchback activity. Nature 1989, 338, 646-648. [CrossRef] [PubMed]

2. De Keuckelaere, E.; Hulpiau, P.; Saeys, Y.; Berx, G.; van Roy, F. Nanos genes and their role in development and beyond. Cell. Mol. Life Sci. 2018, 75, 1929-1946. [CrossRef] [PubMed]

3. Wang, Z.; Lin, H. Nanos maintains germline stem cell self-renewal by preventing differentiation. Science 2004, 303, 2016-2019. [CrossRef] [PubMed]

4. Forbes, A.; Lehmann, R. Nanos and Pumilio have critical roles in the development and function of Drosophila germline stemcells. Development 1998, 125, 679-690. [CrossRef] [PubMed]

5. Subramaniam, K.; Seydoux, G. nos-1 and nos-2, two genes related to Drosophila nanos, regulate primordial germ cell development and survival in Caenorhabditis elegans. Development 1999, 126, 4861-4871. [CrossRef] [PubMed]

6. Tsuda, M.; Sasaoka, Y.; Kiso, M.; Abe, K.; Haraguchi, S.; Kobayashi, S.; Saga, Y. Conserved role of nanos proteins in germ cell development. Science 2003, 301, 1239-1241. [CrossRef] [PubMed]

7. Wang, Y.; Zayas, R.M.; Guo, T.; Newmark, P.A. nanos function is essential for development and regeneration of planarian germ cells. Proc. Natl. Acad. Sci. USA 2007, 104, 5901-5906. [CrossRef] [PubMed]

8. Hansen, C.L.; Pelegri, F. Primordial germ cell specification in vertebrate embryos: Phylogenetic distribution and conserved molecular features of preformation and induction. Front. Cell Dev. Biol. 2021, 9, 730332. [CrossRef] [PubMed]

9. Mochizuki, K.; Sano, H.; Kobayashi, S.; Nishimiya-Fujisawa, C.; Fujisawa, T. Expression and evolutionary conservation of Nanos-related genes in Hydra. Dev. Genes Evol. 2000, 210, 591-602. [CrossRef]

10. Extavour, C.; Akam, M. Mechanisms of germ cell specification across the metazoans: Epigenesis and preformation. Development 2003, 130, 5869-5884. [CrossRef] [PubMed]

11. Rinkevich, B.; Ballarin, L.; Martinez, P.; Somorjai, I.; Ben-Hamo, O.; Borisenko, I.; Berezikov, E.; Ereskovsky, A.; Gazave, E.; Khnykin, D.; et al. A pan-metazoan concept for adult stem cells: The wobbling Penrose landscape. Biol. Rev. 2021, 97, 299-325. [CrossRef] [PubMed]

12. Juliano, C.E.; Swartz, S.Z.; Wessel, G.M. A conserved germline multipotency program. Development 2010, 137, 4113-4126. [CrossRef] [PubMed]

13. Kostyuchenko, R.P.; Kozin, V.V.; Kupriashova, E.E. Regeneration and asexual reproduction in annelids: Cells, genes, and evolution. Biol. Bull. 2016, 43, 185-194. [CrossRef]

14. Özpolat, B.D.; Bely, A.E. Developmental and Molecular Biology of Annelid Regeneration: A Comparative Review of Recent Studies. Curr. Opin. Genet. Dev. 2016, 40, 144-153. [CrossRef]

15. Zattara, E. Axial Regeneration in Segmented Animals A Post-Embryonic Reboot of the Segmentation Process. In Cellular Processes in Segmentation; CRC Press: Boca Raton, FL, USA, 2020; pp. 255-292. ISBN 978-0-429-42360-4. 
16. Nikanorova, D.D.; Kupriashova, E.E.; Kostyuchenko, R.P. Regeneration in Annelids: Cell Sources, Tissue Remodeling, and Differential Gene Expression. Russ. J. Dev. Biol. 2020, 51, 148-161. [CrossRef]

17. Kostyuchenko, R.P.; Kozin, V.V. Comparative Aspects of Annelid Regeneration: Towards Understanding the Mechanisms of Regeneration. Genes 2021, 12, 1148. [CrossRef]

18. Rabinowitz, J.S.; Chan, X.Y.; Kingsley, E.P.; Lambert, J.D. Nanos is required in somatic blast cell lineages in the posterior of a mollusc embryo. Curr. Biol. 2008, 18, 331-336. [CrossRef]

19. Kranz, A.M.; Tollenaere, A.; Norris, B.J.; Degnan, B.M.; Degnan, S.M. Identifying the germline in an equally cleaving mollusc: Vasa and Nanos expression during embryonic and larval development of the vetigastropod Haliotis asinina. J. Exp. Zool. (Mol. Dev. Evol.) 2010, 314B, 267-279. [CrossRef]

20. Kang, D.; Pilon, M.; Weisblat, D.A. Maternal and zygotic expression of a nanos-class gene in the leech Helobdella robusta: Primordial germ cells arise from segmental mesoderm. Dev. Biol. 2002, 245, 28-41. [CrossRef]

21. Ponz-Segrelles, G.; Bleidorn, C.; Aguado, M.T. Expression of vasa, piwi, and nanos during gametogenesis in Typosyllis antoni (Annelida, Syllidae). Evol. Dev. 2018, 20, 132-145. [CrossRef]

22. Zelada-González, F. Germline development in Platynereis dumerilii and its connection to embryonic patterning. In Combined Faculties for Natural Sciences and for Mathematics; Ruperto-Carola University of Heidelberg: Heidelberg, Germany, 2005 ; p. 175.

23. Dill, K.K.; Seaver, E. Vasa and nanos are coexpressed in somatic and germ line tissue from early embryonic cleavage stages through adulthood in the polychaete Capitella sp. I. Dev. Genes Evol. 2008, 218, 453-463. [CrossRef] [PubMed]

24. Gazave, E.; Béhague, J.; Laplane, L.; Guillou, A.; Préau, L.; Demilly, A.; Balavoine, G.; Vervoort, M. Posterior elongation in the annelid Platynereis dumerilii involves stem cells molecularly related to primordial germ cells. Dev. Biol. 2013, 382, 246-267. [CrossRef] [PubMed]

25. Planques, A.; Malem, J.; Parapar, J.; Vervoort, M.; Gazave, E. Morphological, Cellular and Molecular Characterization of Posterior Regeneration in the Marine Annelid Platynereis Dumerilii. Dev. Biol. 2019, 445, 189-210. [CrossRef] [PubMed]

26. Dondua, A.K. Influence of actinomycin D and sibiromycin upon the embryonic and larval development in Nereis virens (Sars.) Ontogenez 1975, 6, 475-484.

27. Dondua, A.K.; Kostyuchenko, R.P.; Fedorova, Z.H.E. Effects of some cytoskeleton inhibitors on ooplasmic segregation in the Nereis virens egg. Int. J. Dev. Biol. 1997, 41, 853-858.

28. Kostyuchenko, R.P.; Dondua, A.K. Ooplasmic segregation and axis formation in the polychaete Nereis virens embryo. Russ. J. Dev. Biol. 2000, 31, 95-105. [CrossRef]

29. Kostyuchenko, R.P.; Dondua, A.K. Development of the prototroch in embryogenesis of Nereis virens (polychaeta). Russ. J. Dev. Biol. 2006, 37, 69-76. [CrossRef]

30. Kozin, V.V.; Filippova, N.A.; Kostyuchenko, R.P. Regeneration of the Nervous and Muscular System after Caudal Amputation in the Polychaete Alitta Virens (Annelida: Nereididae). Russ. J. Dev. Biol. 2017, 48, 198-210. [CrossRef]

31. Shalaeva, A.Y.; Kostyuchenko, R.P.; Kozin, V.V. Structural and Functional Characterization of the FGF Signaling Pathway in Regeneration of the Polychaete Worm Alitta Virens (Annelida, Errantia). Genes 2021, 12, 788. [CrossRef]

32. Kozin, V.V.; Kostyuchenko, R.P. Vasa, PL10, and Piwi gene expression during caudal regeneration of the polychaete annelid Alitta virens. Dev. Genes Evol. 2015, 225, 129-138. [CrossRef]

33. Kostyuchenko, R.P.; Kozin, V.V.; Filippova, N.A.; Sorokina, E.V. FoxA expression pattern in two polychaete species, Alitta virens and Platynereis dumerilii: Examination of the conserved key regulator of the gut development from cleavage through larval life, postlarval growth, and regeneration. Dev. Dyn. 2019, 248, 728-743. [CrossRef]

34. Edgar, R.C. MUSCLE: Multiple sequence alignment with high accuracy and high throughput. Nucleic Acids Res. 2004, 32, 1792-1797. [CrossRef] [PubMed]

35. Dereeper, A.; Guignon, V.; Blanc, G.; Audic, S.; Buffet, S.; Chevenet, F.; Dufayard, J.-F.; Guindon, S.; Lefort, V.; Lescot, M.; et al. Phylogeny.fr: Robust phylogenetic analysis for the non-specialist. Nucleic Acids Res. 2008, 36, W465-W469. [CrossRef]

36. Huelsenbeck, J.P.; Ronquist, F. MRBAYES: Bayesian inference of phylogenetic trees. Bioinformatics 2001, 17, 754-755. [CrossRef] [PubMed]

37. Ronquist, F.; Huelsenbeck, J.P. MrBayes 3: Bayesian phylogenetic inference under mixed models. Bioinformatics 2003, 19, 1572-1574. [CrossRef] [PubMed]

38. Pilon, M.; Weisblat, D.A. A nanos homolog in leech. Development 1997, 124, 1771-1780. [CrossRef]

39. Agee, S.J.; Lyons, D.C.; Weisblat, D.A. Maternal expression of a NANOS homolog is required for early development of the leech Helobdella robusta. Dev. Biol. 2006, 298, 1-11. [CrossRef]

40. Mohri, K.; Nakamoto, A.; Shimizu, T. The ontogeny of nanos homologue expression in the oligochaete annelid Tubifex tubifex. Gene Exp. Patterns 2016, 20, 32-41. [CrossRef]

41. Kozin, V.V.; Filimonova, D.A.; Kupriashova, E.E.; Kostyuchenko, R.P. Mesoderm patterning and morphogenesis in the polychaete Alitta virens (Spiralia, Annelida): Expression of mesodermal markers Twist, Mox, Evx and functional role for MAP kinase signaling. Mech. Dev. 2016, 140,1-11. [CrossRef]

42. Rebscher, N.; Zelada-González, F.; Banisch, T.U.; Raible, F.; Arendt, D. Vasa unveils a common origin of germ cells and of somatic stem cells from the posterior growth zone in the polychaete Platynereis dumerilii. Dev. Biol. 2007, 306, 599-611. [CrossRef] 
43. Rebscher, N.; Lidke, A.K.; Ackermann, C.F. Hidden in the crowd: Primordial germ cells and somatic stem cells in the mesodermal posterior growth zone of the polychaete Platynereis dumerilii are two distinct cell populations. EvoDevo 2012, 18, 9. [CrossRef] [PubMed]

44. Rebscher, N. Establishing the germline in spiralian embryos. Int. J. Dev. Biol. 2014, 58, 403-411. [CrossRef] [PubMed]

45. Kuehn, E.; Clausen, D.S.; Null, R.W.; Metzger, B.M.; Willis, A.D.; Özpolat, B.D. Segment number threshold determines juvenile onset of germline cluster expansion in Platynereis dumerilii. J. Exp. Zool. (Mol. Dev. Evol.) 2021, 1-16. [CrossRef] [PubMed]

46. Bely, A.E.; Sikes, J.M. Latent regeneration abilities persist following recent evolutionary loss in asexual annelids. Proc. Natl. Acad. Sci. USA 2010, 107, 1464-1469. [CrossRef] [PubMed]

47. Özpolat, B.D.; Bely, A.E. Gonad Establishment during Asexual Reproduction in the Annelid Pristina Leidyi. Dev. Biol. 2015, 405, 123-136. [CrossRef] [PubMed]

48. Hill, S.D. Origin of the Regeneration Blastema in Polychaete Annelids. Am. Zool. 1970, 10, 101-112. [CrossRef]

49. Bely, A.E. Early Events in Annelid Regeneration: A Cellular Perspective. Integr. Comp. Biol. 2014, 54, 688-699. [CrossRef] 